\title{
Precision Livestock Tools to Improve Products and Processes in Broiler Production: A Review
}

\section{author(s)}

Mollo MN

Vendrametto $\mathrm{O}$

Okano MT

Graduate Program in Production Engineering. Universidade Paulista - UNIP-SP

\section{Mail Address}

\section{MN Mollo}

R. Dr. Bacelar, 1212

$4^{\circ}$ andar

São Paulo - Brazil

e-mail: mariomollo@gmail.com

vendrameto@unip.br

okano@vop.com.br

\section{ABSTRACT}

Economic growth and production process development require technological support. Technology changes production functions, enabling a higher number of goods to be produced using the same amount of input. In this review, we discuss research and development in information technology that has led to innovative actions, with the new generation of tools, known as precision agriculture tools, that can be applied in Brazilian poultry production. In this context, research and development have focused on producing technological innovations based on increasingly specialized tools that go beyond human mind power, and are related to the acquisition, access, and processing of a huge number of data. The technology generated to date has assimilated the knowledge of experts, transferring it to the computing environment, providing steady, consistent, inexpensive, and fast tools to support decision-making in corporate farms. This will produce more precise and documented decisions, based on accessible and reproducible knowledge. There would be no direct interference of the global market, bringing benefits to producers, consumers, and also ensuring the welfare of birds. This review also highlights the interest of researcher in developing intelligent applications to support best practices, methods, and processes in order to monitor the production chain. It also shows that a few changes may affect the process as a whole, enabling fast decision-making, and promoting a preventative and less aggressive management of birds.

\section{INTRODUCTION}

The excellent status of Brazilian agribusiness accounted in 2007 for $23.7 \%$ of the Gross Domestic Product (GDP), with a significant contribution of broiler production. The 2007/2008 annual report (ABEF, 2008) indicated record results both in terms of volume and revenues. This reinforces the country's position as the world's largest broiler meat exporter, despite the drop in global chicken meat consumption in 2006 due to outbreaks of avian influenza in Asia and Europe (Zullo et al., 2008). The same report (ABEF, 2008) showed that by the end of 2007 chicken meat exports amounted to 3.3 million tons, which represents a $21 \%$ increase relative to 2006 . This was a record performance in the history of Brazilian chicken meat exports. In June 2009, exports totaled 329,000 tons, which indicates a slight drop of $0.34 \%$ as compared to the same period of 2008. Therefore, Brazilian chicken meat exports have occupied a prominent position in the international market, placing the country as the largest world exporter, with a market volume of $49.78 \%$.

However, the good performance achieved by this industry results from a convergence of several positive factors that are directly affected by weather, parents stock adaptation conditions, good broiler 
Mollo MN, Vendrametto 0 , Okano MT

management, including appropriate feeding and manure management, as well good health control. These features are particularly important in Brazil, considering the fact that most broilers are still reared under limited controlled conditions, which are based on the availability of local natural resources. Mitigation actions to reduce the direct impact of this situation on productivity, such as improving broiler environment, as well as management and feeding methods, should be gradually adapted to reduce the possible effects of global warming. Therefore, modern broiler production requires the adoption new concepts and tools to generate technological innovations and to reduce production process losses and costs.

As stated in Tigre (2006), technological innovation is one of the most important determinants of international competitiveness, and the revolution brought by new technologies available to economy and society can lead to innovations in products and processes. Precision tools can be applied for the discovery and characterization of new opportunities of the use of electronics devices, new hardware and software applications, and new types of sensors improve the performance of the broiler production process resulting from the input of innovation technology, with consequent better rearing conditions. This article reviews studies published both by national and international research groups and independent researchers. These studies were based on scientific experiments, approved by ethics committees, and present opportunities for the application of new methods, to change processes, and to introduce new technologies in the broiler production environment.

\section{Technology adoption and competitiveness}

Studies on international competitiveness inputs have their origin in the research of Ricardo (1817), which was based on the comparative advantages of nations and differences in costs of production. These costs depend on the availability of some factors and labor productivity, which is influenced by the technology used in the production process. Therefore, according Tigre (2006), in the Ricardian view, process technology (or production) determines international trade. As far as productivity is concerned, the discussion on development is no longer between rich and poor countries, but between ignorant countries, with little formal education, and countries that are able to generate and absorb new technologies (Drucker, 1988). Technological changes in production processes represent a shift in the production function, allowing
Precision Livestock Tools to Improve Products and Processes in Broiler Production: A Review

the quantity of goods produced to increase while maintaining the amount of inputs used (Tigre, 2006). Many questions have been raised as to the factors that presently limit the increase in productivity, and the emerging knowledge of precision agriculture may be an answer. It is expected that chicken meat production responds to an increasing demand by improving production performance. According to Nääs et al. (2006), the concept of Precision Livestock Production is related to the optimal reduction of losses in the entire production process. Precision farming may provide a new form of agricultural production management. Agricultural production sectors, including broiler production, present different efficiencies, according to the use of precision farming tools. The need to transform steps and processes that can be optimized in these sectors has fueled emerging research on the use of biocompatible sensors, protocols, management information systems, less invasive behavioral monitoring tools, and development of new hardware and software applications to support intelligent decision-making. These tools, along with direct control of the production environment, will allow the optimization of those sectors. The trend is to make broiler production more accurate, with fewer variables that depend on production processes, and more intelligent decisionmaking.

Agricultural businesses generally do not use computerized systems, often relying on empirical notes. However, recording the information inherent to production processes together with financial information is becoming increasingly important not only to meet market demands, but particularly to ensure the control of the internal activities by the managers and to provide support to the companies markets. The adoption of technologies to increase production efficiency has become a reality in Brazilian agriculture. However, information management is still poor, primarily because many entrepreneurs still do not believe in the value of information as a company asset. Much has been discussed and published on the adoption of precision tools to record information related both to crop and livestock production. Many of these tools are already used in other sectors of the economy, but the full adoption of these systems in agribusiness is still recent.

In the agricultural sector, Precision Agriculture makes use of technological resources to individually identify and process data, improving accuracy and allowing higher productivity (McBratney et al, 2005). Research and experiments on animal production have 

Okano MT
Mollo MN, Vendrametto O,

been carried out worldwide using different technologies to support the collected data. All these techniques, individually or in combination, are directly applied to processes of building information systems to improve decision making and production support. Electronic equipment and computerized systems to collect, record, process, and manage production data are tools currently available in broiler production. However, these pieces of equipment and systems need to be integrated to allow supporting each decision in particular. The information collected daily, along with systematic monitoring of production stages, produce important statistics for evaluating, controlling, and promoting possible improvements (Kebeler \& Schiefer, 1996). The use of real-time data collecting systems was studied by Kristensen et al. (2006). The authors developed a dynamic model that could predict the activity of broiler chickens in response to changes in light intensity in order to actively control their activity in the future. In that study, they combined dynamic modeling techniques with traditional statistics to understand the underlying mechanisms that control the activity of broiler chickens. These techniques allow realtime monitoring of birds' activities, reporting them, and making changes in the poultry house equipment, including feeders, fans, and sprinklers, based on the recorded information.

\section{Electronic ID and traceability}

In animal production systems, animal identification is essential. New technologies or those commonly applied in other industries can be used for the purpose of monitoring and managing production. In modern broiler production, the application electronic identification (EID - Electronic Identification) technologies have been studied specially in behavioral studies under different housing conditions. Pereira (2003) identified the limits of the thermoneutral zone of broiler breeders using EID. The author accurately showed using behavioral data recorded with EID that birds present different behaviors according to the environment. This tool allowed that author to identify birds that were more resistant to the harsh weather (essentially hot and dry) that occurred during the experimental period by looking at distribution maps of frequency of use of monitored sites. Despite being effective to quantify behavior, EID did not allow the classification of the recorded behaviors.

Hyun et al. (2007) developed a radio telemetry system devised to measure deep body temperature (DBT) of broilers, in an attempt to control the possible
Precision Livestock Tools to Improve Products and Processes in Broiler Production: A Review

occurrence of diseases. In that study, the authors verified that broiler DBT could be measured with a $0.1^{\circ} \mathrm{C}$ accuracy, and evaluated daily DBT fluctuation of 25day-old broilers. The collected data were used to develop a system that can control broiler house environment in real time based on DBT measurements.

Curto et al. (2002) suggested that monitoring and evaluating breeders' behavior can be a useful tool to evaluate the rearing environment. The objective of their study was to predict breeders' behavior and to relate it to environmental dry bulb temperature (DBT) and relative humidity $(\mathrm{RH})$ using EID. The path used by the female breeders inside the house was recorded, allowing the development of a mathematical model to predict their behavior as a function of DBT and $\mathrm{RH}$ values. The birds tended to stay in cooler places when DBT increased, as described in literature (Bottje et al., 1983; Yanagi et al. 2002). The data recorded the female breeders' real-time response to changes in the house environment because the technology used allowed remote recording without the negative intervention of people nearby the house.

\section{Image analysis and its application}

There is an increasing need of real-time monitoring of broilers in commercial houses, given the complexity of the environmental variables may affect their welfare. The use of specific systems to acquire and process images in real-time enables researchers to study bird behaviors in a non-intrusive manner, and to observe and assess specific events with no human interference. Collins (2008) used video-capture systems to develop a tracking method to investigate the social behavior and preferences of broiler chickens during the production cycle. The objective of that study was to assess the impact of density and social environment on broiler behavior and feeding. The results showed that the broiler flock density seems to have a little direct effect on broiler individual behavior.

In another study with broilers breeders, Pereira et al. (2004) used video cameras and a precision tool to perform a qualitative analysis of broiler breeder behavior. The objective was to demonstrate the feasibility of the use of video cameras to electronically monitor and identify birds' behavioral responses to the environment that could indicate their welfare status. The results showed a direct influence of the rearing environment on the broiler breeders' behavioral responses. The presence of feed was also an experimental factor, and it was demonstrated that it influenced the performance of behaviors related to 
welfare. Dawkins et al. (2009) provided evidences that the optical flow patterns of broiler flock movements recorded on video or CCTV (Closed-circuit Television) inside commercial broiler houses can provide a potentially valuable estimation of broiler welfare. The authors tested the hypothesis that simple descriptive statistics of optical flow patterns (mean, variance, skewness, and kurtosis) differ between flocks and that these differences are correlated with more conventional assessments of welfare, such as mortality and percentage of birds in a flock with leg problems. Dawkins and co-workers expected that there would be a negative correlation between mean optical flow and percentage of birds with poor gait scores, for instance. In an attempt to understand how the behavior of individuals gives rise to the mass effects detected by changes in optical flow, they analyzed the same video sequences and tested that hypothesis. Despite detecting mass movements of whole groups of birds, these movements were correlated with behaviors measured at individual bird level, such as sitting and walking. It was concluded that there were no significant correlations between optical flow measures with flock mortality percentage or leg cull percentage. Nevertheless, there were significant positive correlations of optical flow skewness and kurtosis with flock leg cull percentage. In addition, all four optical flow measures were significantly correlated with gait score. Mean and variance showed strong negative correlations, whereas skewness and kurtosis presented positive correlations. Automated measurements of optical flow, taken remotely from video cameras inside commercial broiler houses may present potential to provide continuous 'outcome' assessment of the welfare state of the flock. While this approach still needs further validation, it has shown the possibility to become a useful tool to minimize the labor-intensive process of gait scoring in broilers, with the major advantage that it could potentially be used to provide continuous outcome measurements of birds during the production cycle.

Using the data obtained by Pereira et al. (2004) and digital-image processing, Nääs et al. (2009) proposed a methodology for estimating thermal comfort in broilers. Bird behavioral responses known to be important welfare indicators were evaluated. An algorithm was developed for classifying specific behaviors of broiler breeders and then transferred to a software application. Videos were recorded within a climatic chamber, where temperature varied according to temperature limits and extremes within the range of thermal neutrality. The digital images were processed, and allowed the detection of a sequence of welfare-related behaviors. The resulting images, after analysis, allowed visualizing the clusters that presented determined behavioral patterns. This may be a step towards real-time recording and continuous welfare assessment of flocks.

\section{Sound analysis and its application}

In the assessment of animal welfare, vocalization analysis is an interesting tool to collect data in a noninvasive manner, and also allows simple automation. Moura (2008) studied the relation between thermal environment and pullet performance. The idea was to estimate thermal comfort by analyzing vocalization magnitude and frequency of pullets reared in tropical conditions. The results showed a correlation between a pullet grouping pattern and vocalization during thermal stress exposure. In the study of Woodcock et al. (2004) to determine if hen's calls at the feeder affect pullets' productivity and welfare, it was found that chicks exposed to recorded hen vocalizations were closer to the speaker than control chicks. This suggests that that pullets try interact with the hen. The acquired behavioral data demonstrated that chicks appear to be attracted to recorded hen vocalizations, remaining close to the speaker. Evidence suggests that hen vocalization improves production during the first nine days post-hatch. Such studies may allow to efficiently mimicking natural stages in order to provide better rearing conditions for broilers in the starter phase.

\section{Housing environmental control}

Broiler housing, together with local environment (climate, topography, and surrounding vegetation) and management systems (stocking density, curtains, equipment, and nutrition), influences bird rearing environment. The spatial distribution of these variables may indicate stress zones within the house. A study conducted by Miragliotta et al. (2006) applied spatial analysis of environmental temperature, air, and noise conditions inside a broiler house with tunnel ventilation and a flock density of 18 birds $\mathrm{m}^{-2}$. The authors concluded that the stress zones were located at both ends of the house, and the highest mortality rate was found in the west, where the exhausting system was located. Spatial analysis may be an important tool to determine the performance of ventilation and cooling systems, as well as air quality inside broiler houses.

A system based on a dynamic flow chamber was designed to measure ammonia emissions from poultry 
Mollo MN, Vendrametto O, Okano MT

Precision Livestock Tools to Improve Products and Processes in Broiler Production: A Review

litter and to investigate ammonia emissions responses under controlled laboratory conditions (Liu et al., 2007). It was observed that ammonia emissions were very sensitive to litter moisture. Total nitrogen content increased with increasing litter humidity, indicating that this may potentially increase ammonia emissions. However, measurements of ammonia levels and total nitrogen losses in litter suggested when water was applied, it suppressed ammonia emissions for a short period of time. These results may allow researchers to develop joint systems for ammonia emission analysis, enabling mitigation measures to be taken by the algorithms implemented in the automatic controllers when levels become critical.

Pawar et al. (2007) used Computational Fluid Dynamics (CFD) to determine disease-spread characteristics and to compare two ventilation schemes, simulating air ventilation both inside and around poultry houses. The two ventilation systems showed striking differences in their temperature and contaminant diffusion patterns. Temperature contours revealed that the top-to-bottom ventilation system was not as effective at cooling as the bottom-to-top system. The temperature of most of the air volume inside the poultry house was close to that outside the house in the bottom-to-top system, which did not happen with the top-to-bottom ventilation system. The authors also calculated $\mathrm{NH}_{3}$ diffusion contours and showed the amount of $\mathrm{NH}_{3}$ diffusing into an adjacent (downwind) poultry house using the CFD analysis. The analysis reported that, from the point of view of temperature control and the spread of airborne virus particles to neighboring poultry houses, the ventilation system using the airflow from bottom to top was much better than that with airflow from top to bottom. As air quality is becoming an important environmental issue, the study of this issue is essential for future poultry production.

\section{Data mining and knowledge acquisition}

According to Vale (2008), one of the most promising techniques of data search is Data Mining, which allows modeling large volumes of data involving multiple variables (Fayyad \& Stolorz, 1997). Within databases, essential knowledge may be expressed in the form of patterns, which perhaps are relevant to the field to which they relate. The correct use of these databases requires the application of computational techniques, such as those based on machine learning for automatic acquisition of knowledge, which patterns can be extracted to understand events and to make predictions. That study estimated the incidence of heat waves that cause production losses, and consequently economic losses, due to broiler exposure to heat stress. The use of a production management database and historical weather data allowed modeling bird mortality due to the incidence of heat waves. Attributes for classification (decision trees) were selected to model the impact of heat waves on broiler mortality, and it was concluded that this technique can be applied to build up predictive models for animal production. The choice of Data Mining amongst other mathematical techniques and tools relative to conventional statistics allows the analysis of continuous or discontinuous numerical and symbolic data, enabling working with hypotheses that were not previously raised (McQueen et al., 1995). Likewise, Zhang et al. (2005) compared decision trees to regression models for the prediction of pasture productivity, and obtained lower mean square error and higher certainty percentage $(90 \%$ of cases, $10.8 \%$ higher than regression analysis) using decision trees.

\section{Electronic sensors}

The current integrated monitoring and control processes require specific resources to optimize human labor. Temperature, humidity, and wind speed sensors, microphones, and other pieces of equipment are becoming more affordable for common use, and are key to obtain input data for these integrated systems. These sensors have been experimentally applied to monitor poultry farms, increasing the volume of information for researchers. Pressure sensors have also been used to assess walking ability of humans and animals. Nääs et al. (2008) conducted a research study that aimed at evaluating broiler locomotion ability, analyzing the peaks of pressures in the legs during walking. A chamber with transparent acrylic walls and an entrance ramp, a horizontal plateau in the middle and an exit ramp, was built. A thin mat with piezoelectric crystal sensors was placed on the horizontal plateau for recording the pressure of walking, and a software application displayed the digitally recorded images of pressures and processed and analyzed the data. Birds were encouraged to walk on the platform, and the pressure of both feet was automatically recorded separately. The software application was set up in a desktop computer, and data were saved for further analysis, as used in earlier studies (Carvalho et al., 2005; Oviedo-Rondón, 2007). Results showed that gait score increased as bird weight and age increased. Although not visually identified, the results using the measurement system showed that 
Mollo MN, Vendrametto 0 , Okano MT the peak force were different between the right and the left legs, causing slow and uneven walking, and further leg problems in older birds.

Using the same concept, Corr et al. (2006) tested the force plate as a gait analysis system for broilers to determine how the ground reaction force (GRF) patterns change in these birds with growth and administration of analgesia. The results showed that the interaction of analgesia with feeding was not statistically significant ( $p>0.05)$ in all measurements, i.e., effect magnitude was similar both in ad libitum and restricted-fed birds, and the average provided a more precise estimate. The authors concluded that the force plate is a suitable research tool for recording GRFs from avian bipeds, and that large mediolateral forces identify a particularly inefficient aspect of avian gait; however, the role of pain remains to be determined.

\section{Expert systems}

There are several applications and uses of information technology than can be used in the broiler industry, as reported by Lopes (1997) and Lopes (2002). The development of expert software applications to aid producers and traders to make the right decisions at a specific time is noteworthy. The cost of wrong decisions tends to rise with fierce market competition. The development of information management, both internal and external to the agribusiness companies, specific for each country, is becoming increasingly important (Noronha \& Peres, 1992). The broiler industry is currently as complex and dynamic as other industries, requiring from the producer a new vision of business management, particularly that of abandoning the traditional farmer perspective to become an entrepreneur (Yamaguchi \& Carneiro, 1997).

The basis of expert systems is simply to obtain knowledge from the fields of interest, with its vast body of details on specific actions, and transfer it from humans to a computer-based system. This knowledge is then stored and users may use it as needed. According to Turban \& Aronson (2001), the computer system can make inferences, provide warnings, the rationale behind the warning, and reach specific conclusions.

Schoemaker (1993) states that: "The strategic decisions are crucial to the viability of companies and are defined as intentional choices or programmed responses to the situations that materially affect the outlook, well-being and the nature of the organization's survival". These elements tend to guide the organization in the future and shape its course. Animal
Precision Livestock Tools to Improve Products and Processes in Broiler Production: A Review

precision tools generate specific knowledge, and in general enable researchers to build decision algorithms based on research and deep analysis of research data. The associations and correlations found between the knowledge and skills of one or more of these experts need to be transferred to software programs to be disseminated. Developing specific expert systems is important to support decision-making in poultry production, using interfaces with equipment to provide optimal rearing conditions, such as activation of fans, sprinklers, curtains, feeding systems, etc.

\section{Final remarks}

Agribusiness companies, farmers and chicken meat exporters need to increased their efforts in research and development to cope with current and future business and technical challenges. This will help them to search for increasingly specialized tools based on technological innovations and to invest in their ability to adapt traditional procedures and processes. Intelligent and expert systems, built by algorithms based on data collection and processing tools supported by animal precision concepts, may replace human experts' decisions. In this future scenario, specific decisions will be more adequate and well documented, and based on accessible and reproducible knowledge without external influences of any kind.

Environmental awareness and social responsibility are increasingly demanding significant changes in international trade. The technologies mentioned in this article are primarily meant to provide good overall rearing conditions to the birds during their lifetime, and consequently higher productivity. The development of intelligent applications that support best practices, methods, and processes to monitor the production chain enables data acquisition and subsequent input information from the process as a whole. This information will then allow faster and more precise preventive decision-making, turning broiler production into a more accurate business, less dependent on random factors.

\section{REFERENCES}

ABEF - Brazilian Association of Producers and Exporters of Chicken, Annual Report 2007/2008. [cited 2008 nov]. Available from: http:/ /www.abef.com.br.

Bottje WG, Harrison PC, Grishaw, D. Effect of an acute heat stress of blood flow the artery of husband cockerels. Poultry Science $1983 ; 62: 386-387$ 
Carvalho VRR, Bucklin RA, Shearer JK, Shearer L. Effects of trimming on dairy cattle hoof weight bearing and pressure distributions during the stance phase. Transactions of the ASAE 2005; 48(4): 1653-1659.

Collins LM. Non-intrusive tracking of commercial broiler chickens in situ at different stocking densities. Applied Animal Behavior Science 2008; 112(1-2):94-105.

Curto FPF, Nääs IA, Pereira DF, Salgado DD, Murayama M, Behrens F. Predicting broiler breeder's behavior using electronic identification. Agricultural Engineering International: The CIGR Journal of Scientific Research and Development 2002; 4:323-329.

Dawkins MS, Lee HJ, Waitt CD, Roberts SJ. Optical flow patterns in broiler chicken flocks as automated measures of behaviour and gait. Applied Animal Behaviour Science 2009; 119(3-4):203-209.

Drucker P. From Capitalism to knowledge society. In: Neef D, editor. The knowledge economy. Woburne: Butterworth- Heinemann; 1988. chapter 2. p.15-34.

Fayyad U, Stolorz P. Data mining and KDD: Promise and challenges. Future Generation Computer Systems 1997; 13:99-115.

Hyun HY, Yeong HB, Wongi M. Implantable wireless sensor network to monitor the deep body temperature of broilers. Proceedings of the 5th ACIS International Conference on Software Engineering Research, Management and Applications; 2007. p. 513-517.

Kebeler T, Schiefer G. Computer aided environmental control to support environmental-management-systems in agricultural and food-industrial production-chains. Department of Agricultural Economics; 1996.

Kristensen HH, Aerts JM, Leroy T, Wathes CM, Berckmans D. Modeling the dynamic activity of broiler chickens in response to step-wise changes in light intensity. Applied Animal Behaviour Science 2006; 101(1-2):125-143.

Liu Z, Wang L, Beasley D, Oviedo E. Effect of moisture content on ammonia emissions from broiler litter: a laboratory study. Journal of Atmospheric Chemistry 2007; 58(1):41-53.

Lopes MA. Information technology applied to cattle. Jaboticabal: FUNEP; 1997

Lopes MA. Information technology applied to dairy cattle. Lavras: UFLA; 2002. p. 130.

McBratney A, Bouma J, Whelan B, Ancev T. Future directions of precision agriculture. Wageningen: Springer Netherlands Publisher; 2005. p.7-23.

McQueen RJ, Garner SR, Nevill-Manning CG, Witten IH. Applying machine learning to agricultural data. Computers and Electronics in Agriculture 1995; 12:275-293.

Miragliotta MY, Naas, IA, Manzione RLE, Nascimento F. Spatial analysis of stress conditions inside broiler house under tunnel ventilation. Scientia Agricola 2006; 63(5):426-432.
Moura DJ, Nääs IA, Alves ECS, Carvalho TMR, Vale MM, Lima KAO. Noise analysis to evaluate chick thermal comfort. Scientia Agricola 2008; 65(4):438-443.

Nääs IA, Laganá M, Mollo NM. Estimating broiler breeder welfare using image analysis. Proceedings of 7th World Congress of Computers in Agriculture and Natural Resources; 2009; Reno. Nevada. p. 22-24.

Nääs IA, Carvalho VC, Moura DJ, Mollo MN. Animal behaviour analysis; signal and image processing approach. In: Axel Munack $A$, editor. Handbook of agricultural engineering. Michigan: International Commission of Agricultural Engineering; 2006. p. 313-325.

Nääs IA, Sonoda LT, Romanini CEB, Morello GM, Neves HAF, Baracho MS, Souza SRL, Mollo MN, Menezes AG, Moura DJ, Almeida P ICL. Morphological asymmetry and broiler welfare. Brazilian Journal of Poultry Science 2008; 10:203-207.

Noronha JF, Peres FC. Future directions of rural management. In: Update Week Administration Rural, 1992, Lages, SC Anais: Florianópolis: EPAGRI / CTA Planalto Serrano Santa Catarina; 1992; p. 251-260.

Oviedo-Rondón EO. Predisposing factors that affect walking ability in turkeys and broilers [cited $2007 \mathrm{dec}$ ]. Available from: http:// www.ces.ncsu.edu/depts/poulsci/conferenceproceedings/ nutrition_conference/2007/oviedo_2007.pdf.

Pawar SR, Cimbala JM, Wheeler EF, Lindberg DV. Analysis of poultry house ventilation using computational fluid dynamics. Transactions of the ASAB 2007; 50(4):1373-1382.

Pereira DF. Assessment of the behaviour of individual breeders (broilers) depending on the environment and identification of the critical maximum temperature [thesis]. Campinas (SP): UNICAMP Faculty of Agricultural Engineering; 2003.

Pereira DF, Nääs IA, Romanini CEB, Salgado DD. Assessment of behavioral responses of arrays of broilers in climatic chamber. Proceedings of $33^{\circ}$ Brazilian Congress of Agricultural Engineering; 2004; São Pedro, São Paulo. Brasil.

Ricardo D. Principles of political economy and taxation. London; 1817.

Schoemaker PJH. Strategic decisions in organizations: rational and behavioral views. Journal of Management Studies 1993; 30(1): 107-129.

Tigre PB. Innovation management: the economics of technology in Brazil. 2nd ed. Rio de Janeiro: Eselvier; 2006

Turban E, Aronson JE. Decision Support systems and intelligent systems. 6th ed. Hong Kong: Prentice International Hall; 2001.

Vale MM, Moura DJ, Nääs IA, Oliveira SRM, Rodrigues LHA. Data mining to estimate broiler mortality when exposed to heat wave. Scientia Agricola 2008; 65(3):223-229.

Woodcock MB, Pajor EA, Latour MA. The effects of hen vocalizations 
on chick feeding behavior. Poultry Science 2004; 83(12):19401943.

Yamaguchi LCT, Carneiro AV. Spreadsheet application in technical and economic analysis unit of milk production. Proceedings of the Congress of the Brazilian Society of Information Technology Applied to Agriculture and Agribusiness; 1997; Belo Horizonte: SBIAGRO; 1997. p.95-99.

Yanagi JRT, Xin H, Gates RS. A research facility for studying poultry responses to heat stress and its relief. Applied Engineering in Agriculture 2002; 18(2):255-260.

Zhang B, Valentine I, Kemp P. Modelling the productivity of naturalized pasture in the north island, New Zeland: a decision tree approach. Ecological Modelling 2005; 186:299-311.

Zullo JJ, Assad ED, Pinto HS. Changes must move crops. Scientific American Brazil 2008; 74:72-77. 